\title{
Timing of Adiposity Rebound and Adiposity in Adolescence
}

WHAT'S KNOWN ON THIS SUBJECT: Earlier adiposity rebound may increase fatness in later life; however, there is limited evidence from large cohorts of contemporary children with direct measures of fatness in adolescence or adulthood.

WHAT THIS STUDY ADDS: Early adiposity rebound is strongly associated with increased BMI and fatness in adolescence. Future preventive interventions should consider targeting early childhood to delay timing of adiposity rebound.
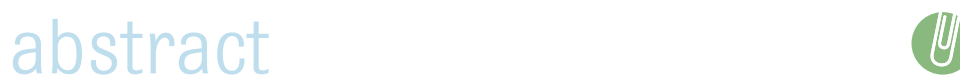

OBJECTIVES: To investigate associations between timing of adiposity rebound (AR; the period in childhood where BMI begins to increase from its nadir) and adiposity (BMI, fat mass) at age 15 years in the Avon Longitudinal Study of Parents and Children (ALSPAC).

METHODS: The sample consisted of 546 children with AR derived in childhood and BMI and fat mass index (FMl; fat mass measured by dual-energy radiograph absorptiometry/height in $\mathrm{m}^{2}$ ) measured at 15 years. Multivariable linear regression models were based on standardized residuals of log BMl and log FMl to allow comparison of regression coefficients across outcomes.

RESULTS: There were strong dose-response associations between timing of $A R$ and both adiposity outcomes at 15 years independent of confounders. BMl was markedly higher in adolescence for those with very early $A R$ (by 3.5 years; $\beta=0.70$; 95\% confidence interval [Cl]: $0.33-1.07 ; P \leq .001)$ and was also higher for those with early AR (between 3.5 and 5 years; $\beta=0.34 ; 95 \% \mathrm{Cl}$ : $0.08-0.59 ; P=.009$ ) compared with those with later AR ( $>5$ years) after full adjustment for a range of potential confounders. Similar magnitudes of association were found for FMl after full adjustment for confounders (compared with later AR: very early $\mathrm{AR} \beta=0.74$; $95 \% \mathrm{Cl}$ : $0.34-1.15 ; P \leq .001$; early AR $\beta=0.35 ; 95 \% \mathrm{Cl}: 0.07-0.63 ; P=.02$ ).

CONCLUSIONS: Early AR is strongly associated with increased BMI and FMI in adolescence. Preventive interventions should consider targeting modifiable factors in early childhood to delay timing of AR. Pediatrics 2014;134:e1354-e1361
AUTHORS: Adrienne R. Hughes, PhD, ${ }^{a}$ Andrea Sherriff, PhD, ${ }^{\text {b }}$ Andrew R. Ness, PhD, ${ }^{c, d}$ and John J. Reilly, PhD ${ }^{a}$

aphysical Activity for Health, School of Psychological Sciences and Health, University of Strathclyde, Glasgow, United Kingdom; ${ }^{b}$ College of Medical, Veterinary Life Sciences, University of Glasgow Dental School, Glasgow, United Kingdom; 'The UK National Institute for Health Research Bristol Nutrition Biomedical Research Unit in Nutrition, Diet, and Lifestyle at University Hospitals Bristol NHS Foundation Trust and ${ }^{d}$ The University of Bristol, Level 3, University Hospitals Bristol Education Centre, Bristol, United Kingdom

KEY WORDS

adiposity rebound, early childhood, adolescents, obesity, adiposity, BMI, ALSPAC

\section{ABBREVIATIONS}

ALSPAC—Avon Longitudinal Study of Parents and Children AR-adiposity rebound

CiF-Children in Focus

FMl-fat mass index

Dr Reilly conceptualized and designed the study, interpreted data analyses, wrote the first draft of the manuscript, reviewed subsequent drafts, and serves as a guarantor for the contents of this manuscript; Dr Hughes designed the study, conducted and interpreted data analyses, wrote the first draft of the manuscript, revised subsequent drafts, and serves as a guarantor for the contents of this manuscript; Dr Sherriff designed the study, supervised and interpreted data analyses, contributed to writing the first draft of the manuscript, and reviewed subsequent drafts; Dr Ness interpreted data analyses and critically reviewed drafts of the manuscript; and all authors approved the final manuscript as submitted.

www.pediatrics.org/cgi/doi/10.1542/peds.2014-1908

doi:10.1542/peds.2014-1908

Accepted for publication Aug 25, 2014

Address correspondence to Adrienne R. Hughes, PhD, University of Strathclyde, School of Psychological Sciences and Health, 50 George St, Glasgow, G1 1Q̨E, UK. E-mail: adrienne.hughes@strath. ac.uk

PEDIATRICS (ISSN Numbers: Print, 0031-4005; Online, 1098-4275) Copyright (C) 2014 by the American Academy of Pediatrics FINANCIAL DISCLOSURE: The authors have indicated they have no financial relationships relevant to this article to disclose.

FUNDING: The UK Medical Research Council and the Wellcome Trust (grant 092731) and the University of Bristol provide core support for Avon Longitudinal Study of Parents and Children (ALSPAC). No external funding was secured for the current study.

POTENTIAL CONFLICT OF INTEREST: The authors have indicated they have no potential conflicts of interest to disclose. 
Adiposity rebound (AR), ${ }^{1}$ the period in childhood in which BMl begins to increase from a nadir, historically occurred between 5 and 7 years. ${ }^{1,2}$ There is some evidence that early AR (defined as younger age at onset) predicts substantially increased risk of obesity in later life as defined by $\mathrm{BMI}^{1-6}$ and other proxies for fat mass (waist circumference and skinfold thickness). ${ }^{7-9}$ However, the literature on timing of AR and later risk of obesity is limited in many respects, consisting largely of older studies conducted before the pediatric obesity epidemic and/or of small studies with relatively short follow-up or with a limited range of outcomes (usually only proxies for obesity). ${ }^{2}$ Few studies have examined the influence of timing of AR on directly measured fat mass in adolescence or adulthood. ${ }^{10} \mathrm{~A}$ recent study by Ohlsson et a $1{ }^{10}$ found that early age at AR $(<5.4$ years of age) was associated with higher BMl and fat mass (measured by dual-energy radiograph absorptiometry) in young men $(n=573)$. However, these findings are limited to men, timing of AR was determined from retrospective childhood data, and the analyses did not adjust for factors that may confound the relationship between AR timing and later fatness. Overall, no studies have provided a definitive test of the influence of timing of AR on obesity and fatness in adolescence or adulthood.

The primary aim of the current study was therefore to investigate associations between timing of $A R$ in early childhood and measures of adiposity (BMI-for-age and directly measured fat mass) at age 15 years in a large cohort of contemporary children studied after the pediatric obesity epidemic was underway in the United Kingdom.

\section{METHODS}

We used data from the Avon Longitudinal Study of Parents and Children (ALSPAC; http://www.alspac.bris.ac.uk), which is an ongoing population-based study investigating a wide range of influences on health and development of children. Ethical approval for the study was obtained from the ALSPAC Ethics and Law Committee and the Local Research Ethics Committees. ALSPAC recruited 14541 pregnant women residing in Avon, United Kingdom, with expected dates of delivery Apri1 I, 1991, to December 31, 1992. A total of 14541 is the initial number of pregnancies for which the mother enrolled in the ALSPAC study and had either returned at least 1 questionnaire or attended a "Children in Focus" (CiF) clinic by July 19, 1999. Of these initial pregnancies, there was a total of 14676 fetuses, resulting in 14062 live births and 13988 children who were alive at 1 year of age. A $10 \%$ sample of the ALSPAC cohort, known as the Cif group, attended clinics at the University of Bristol at various time intervals between 4 and 61 months of age. The CiF group was chosen at random from the last 6 months of ALSPAC births (1432 families attended at least 1 clinic). Excluded were those mothers who had moved out of the area or were lost to follow-up and those partaking in another study of infant development in Avon. From age 7 onward, the entire ALSPAC cohort (including the CiF group) were invited to attend regular research clinics. The phases of enrollment to ALSPAC are described in more detail elsewhere. ${ }^{11}$ The study Web site contains details of all the data that are available through a fully searchable data dictionary (http://www.bris.ac. uk/alspac/researchers/data-access/ data-dictionary).

\section{Study Design and Procedures}

Analyses were conducted in participants of the CiF group who had provided serial measures of BMI in early childhood (by attending research clinics up to 61 months) from which timing of AR was derived and who had provided a BMI measure at the 15-year research clinic.
Height, Weight, BMI, and Weight Status

At each research clinic, subjects' weight was measured to the nearest $0.1 \mathrm{~kg}$ and height to the nearest $0.1 \mathrm{~cm}$ while wearing light clothing with shoes and socks removed. Weight status was defined by using BMI $z$ scores relative to UK 1990 BMl reference data12: overweight (BMl $z$ score $\geq 1.04$ and $<1.64$, equivalent to 85th-94th percentiles) and obese (BMl $z$ score $\geq 1.64$, equivalent to $\geq 95$ th percentile). These definitions have specificity and high sensitivity relative to direct measures of excessive fatness in the ALSPAC cohort. ${ }^{13,14}$

\section{Timing of AR in Childhood (Exposure)}

Timing of AR was determined by using the "gold standard" method, ${ }^{1,15}$ which involved visual inspection of individual BMl-for-age plots to identify when the increase in BMl took place after the nadir, as described previously. ${ }^{16}$ The following additional criteria were applied to reduce any subjectivity in the assessment and to avoid basing judgments on changes in BMl that were within the limits of measurement error: (1) all consecutive measurements of $\mathrm{BMI}$ after the nadir had to show an increase and (2) any increase in BMl after the nadir had to equal or exceed $0.1 .^{16}$ Timing of AR was categorized into 3 groups as follows: very early (by 43 months of age), early ( $>43$ months and $\leq 61$ months of age), and later ( $>61$ months of age). ${ }^{16}$

\section{Outcome Measures at 15 Years}

Two indices of adiposity were used as outcome measures: BMl-for-age and fat mass index (FMI). A high BMI-for-age has high sensitivity and very high specificity as a means of identifying individuals with excessive fat mass. Fat mass is a more direct measure of adiposity that provides greater sensitivity and power ${ }^{17}$ and was measured by using a Lunar Prodigy dual-energy radiograph 
absorptiometry scanner (GE Medical Systems, UK), as described previously. ${ }^{18}$ FMI was calculated as fat mass (kg)/ height $\left(m^{2}\right) .3,18$

\section{Potential Confounders}

A number of potential confounders were included, as follows: child age at the 15-year clinic, gender, parity, gestation, birth weight, socioeconomic position on the basis of maternal education (none/Certificate of Secondary Education to university degree or above) and household social class (I [professional/ managerial] to $\mathrm{V}$ [unskilled manual workers] as classified by the 1991 UK Office of Population Census and Surveys, ${ }^{19}$ having at least 1 obese parent (on the basis of maternal and paternal selfreported BMI prepregnancy), maternal smoking in pregnancy (on the basis of questionnaire responses from all 3 trimesters), and pubertal status (1 [least advanced] to 5 [most advanced] on the basis of Tanner pubic hair development for males and most advanced stage for pubic hair and breast development for females assessed at the 15-year clinic. Full details of how these variables were assessed are provided in the Supplemental Information.

\section{Statistical Power}

Power was fixed by the size of the subsample and so no formal power calculation was carried out. However, the sample size available at follow-up is 1 of the largest studies to date on the long-term outcome of timing of AR. Previous studies have found associations between timing of $A R$ and obesity in smaller samples, in part because of the strength of the associations between timing of $A R$ and later obesity. ${ }^{1-10}$

\section{Statistical Analyses}

Means and SDs were calculated for continuous variables that were approximately normally distributed, medians and interquartile ranges for skewed variables, and proportions for categorical variables. Adiposity measures at 15 years (BMI $z$ score, fat mass [kg], FMl, percentage of body fat, and weight status) were described by AR category. BMI and FMI at 15 years were treated as continuous variables, which were logged because of their skewed distribution, and further analysis by using multivariable linear regression (described below) was based on standardized residuals of $\log \mathrm{BMI}$ and $\log \mathrm{FMI}$ to allow comparison of regression coefficients across outcome measures. From this point onward we refer to standardized residuals of log BMl and log $\mathrm{FMl}$ as BMl and FMI.

\section{Modeling Strategy}

Associations between timing of AR (exposure variable) and outcomes (on the basis of measures of BMl and FMl at 15 years) were tested by using multivariable linear regression models. We formally tested the association between timing of AR and outcomes for an interaction with gender. There were no interactions $(P>.3$ for $\mathrm{BMI}$ and $\mathrm{FMl})$; therefore, all models were fitted for boys and girls together. A series of models were used to explore the extent of the attenuation of the association between timing of AR and outcomes. 18,21,22 Model 1 (minimally adjusted) was adjusted for age at the 15-year clinic and gender. Model 2 adjusted for variables in model 1 plus parity, maternal education, household social class, at least 1 obese parent, any smoking in pregnancy, gestational age, and birth weight. The final model (model 3) adjusted for the variables in model 2 plus pubertal status at age 15. Pubertal stage was added separately because this variable had a large amount of missing data.

The impact of missing data was assessed ${ }^{18,21-24}$ by comparing character- istics between participants who provided BMI data at the age 15-year clinic and those who did not attend the clinic or those who attended but did not provide BMI data. To assess whether any change in regression coefficients in models 2 and 3 was due to the confounders rather than due to bias relating to missing data, model 1 (minimally adjusted) was repeated restricting to only those participants who had complete data in model 3 (complete confounder information). SPSS version 20 (IBM SPSS Statistics, IBM Corporation, Armonk, NY) was used for all analyses.

\section{RESULTS}

The timing of AR was derived for 907 children; $6.9 \%(n=63)$ of children had experienced "very early AR" (by 43 months), $20.3 \%$ ( $n=184$ ) had experienced "early AR" (between 44 and 61 months), and $72.8 \%(n=660)$ had rebounded later ( $>61$ months). The majority of characteristics were similar across AR categories (see Table 1). BMl $z$ scores were similar across AR categories at 37 months (ie, before the rebound had occurred) but were higher in the very early and early AR categories at 61 months and 7 years, respectively (ie, after rebound had occurred in these categories; see Fig 1). All adiposity measures at 15 years (ie, BMI $z$ score, fat mass [kg], FMl, percentage body fat, and weight status) were substantially higher in those with very early AR than in those with early AR and later AR (see Table 2 and Fig 1).

Of the 907 children for whom AR was derived, 546 (60.2\%) had BMl outcome data at age 15 and 520 (57.3\%) had FMI outcome data. See Supplemental Tables 4 and 5 for comparison of characteristics between participants who provided BMI data at the 15-year research clinic and those who did not provide BMI data at 15 years. 


\begin{tabular}{|c|c|c|c|c|c|c|c|}
\hline & \multicolumn{2}{|c|}{$\begin{array}{c}\text { Very Early AR ( } \leq 43 \\
\text { Months) }(n=63)\end{array}$} & \multicolumn{2}{|c|}{$\begin{array}{l}\text { Early AR (by } 61 \text { Months) } \\
\qquad(n=184)\end{array}$} & \multicolumn{2}{|c|}{$\begin{array}{c}\text { Later AR (>61 Months) } \\
\qquad(n=660)\end{array}$} & \multirow[t]{2}{*}{ Difference $(P)$} \\
\hline & $n$ & Value & $n$ & Value & $n$ & Value & \\
\hline Gender, $n$ (\%) & 63 & & 184 & & 660 & & .18 \\
\hline Boys & & $28(44.4)$ & & $96(52.2)$ & & $369(55.9)$ & \\
\hline Girls & & $35(55.6)$ & & $88(47.8)$ & & $291(44.1)$ & \\
\hline Birth weight, mean \pm SD, g & 63 & $3460.0 \pm 537.1$ & 183 & $3461.5 \pm 536.8$ & 655 & $3454.6 \pm 527.9$ & .99 \\
\hline Gestation, mean \pm SD, wk & 63 & $39.7 \pm 1.3$ & 184 & $39.3 \pm 1.6$ & 660 & $39.5 \pm 1.7$ & .11 \\
\hline Parity, $n(\%)$ & 62 & & 179 & & 647 & & .25 \\
\hline 0 & & $36(58.1)$ & & $85(47.5)$ & & $295(45.6)$ & \\
\hline 1 & & $14(22.5)$ & & $63(35.2)$ & & $214(33.1)$ & \\
\hline$\geq 2$ & & $12(19.4)$ & & $31(17.3)$ & & $138(21.3)$ & \\
\hline Maternal education, $n$ (\%) & 63 & & 179 & & 645 & & .81 \\
\hline None/CSE & & $5(7.9)$ & & $17(9.5)$ & & $73(11.4)$ & \\
\hline Vocational & & $4(6.3)$ & & $22(12.3)$ & & $58(9.0)$ & \\
\hline 0 level & & $26(41.3)$ & & $67(37.4)$ & & $226(35.0)$ & \\
\hline A level & & $19(30.2)$ & & $48(26.8)$ & & 189 (29.3) & \\
\hline Degree & & $9(14.3)$ & & $25(14.0)$ & & 99 (15.3) & \\
\hline Household social class, $n$ (\%) & 57 & & 171 & & 607 & & $.77^{\mathrm{a}}$ \\
\hline I (professional) & & $7(12.3)$ & & $26(15.2)$ & & 96 (15.9) & \\
\hline$\|$ & & $29(50.8)$ & & $77(45.0)$ & & $288(47.4)$ & \\
\hline III (nonmanual) & & $17(29.8)$ & & $48(28.1)$ & & $135(22.2)$ & \\
\hline III (manual) & & $2(3.5)$ & & $12(7.0)$ & & $59(9.7)$ & \\
\hline IV & & $1(1.8)$ & & $6(3.5)$ & & $24(4.0)$ & \\
\hline V (unskilled) & & $1(1.8)$ & & $2(1.2)$ & & $5(0.8)$ & \\
\hline At least 1 obese parent, $n$ (\%) & 50 & $14(28.0)$ & 147 & $28(19.0)$ & 474 & $66(13.9)$ & .02 \\
\hline Any smoking in pregnancy, $n$ (\%) & 58 & $8(13.8)$ & 171 & $29(17.0)$ & 631 & $120(19.0)$ & .55 \\
\hline \multicolumn{8}{|l|}{ BMl $z$ score, mean $\pm S D^{b}$} \\
\hline 37-Month clinic & 57 & $0.44 \pm 0.97$ & 175 & $0.20 \pm 0.93$ & 620 & $0.31 \pm 0.95$ & .19 \\
\hline 61-Month clinic & 63 & $1.32 \pm 0.96$ & 184 & $0.50 \pm 0.90$ & 660 & $0.12 \pm 0.90$ & $<.001$ \\
\hline 7-Year clinic & 55 & $1.24 \pm 1.16$ & 164 & $0.26 \pm 1.03$ & 572 & $-0.03 \pm 0.96$ & $<.001$ \\
\hline Pubertal stage at 15 -year clinic, $n(\%)$ & 38 & & 99 & & 347 & & $.45^{\mathrm{c}}$ \\
\hline 1 (least advanced) & & 0 & & 0 & & $1(0.3)$ & \\
\hline 2 & & 0 & & $2(2.0)$ & & $4(1.2)$ & \\
\hline 3 & & $2(5.2)$ & & $9(9.1)$ & & $30(8.6)$ & \\
\hline 4 & & $18(47.4)$ & & $48(48.5)$ & & $191(55.0)$ & \\
\hline 5 (most advanced) & & $18(47.4)$ & & $40(40.4)$ & & $121(34.9)$ & \\
\hline
\end{tabular}

CSE, Certificate of Secondary Education.

${ }^{a} \chi^{2}$ based on combined groups (I, II vs III-V).

${ }^{b}$ BMl $z$ scores calculated by using the UK 1990 population reference data. ${ }^{12}$

${ }^{\mathrm{c}} \chi^{2}$ based on combined groups ( $1-3$ vs 4 vs 5 ).

\section{Associations Between Timing of AR} and Adiposity at Age 15 Years

Table 3 shows the associations between timing of AR and adiposity outcomes (on the basis of measures of BMI and FMI) at 15 years. In all models (models 1-3) BMl and FMl at age 15 were higher in children with very early and early AR compared with those with later AR (Table 3). In the minimally adjusted model, children who had experienced very early AR (by 43 months) had an almost 1-SD increase in BMl and FMl at age 15 when compared with those who experienced later AR (>61 months).
When all potential confounders were taken into account, this effect attenuated to two-thirds of a SD. Children who had experienced early AR (between 44 and 61 months) had an increase in the SD of one-third in BMl and FMl at age 15 compared with those who experienced later AR ( $>61$ months) in the minimally adjusted model, and adjustment for all potential confounders did not change the regression coefficients. Further analysis revealed that the attenuation of the regression coefficients in the very early AR group were mainly due to having at least 1 obese parent, which was more prevalent in the very early group (28\%) compared with the later group (13.9\%). We repeated model 1 in those with complete data on all confounders and the regression coefficients remained similar (see Supplemental Table 6).

\section{DISCUSSION}

In the current study, we found a strong "dose response" association between timing of AR and both adiposity outcomes at age 15 years, independent of a range of confounders, with similar magnitudes of association across BMI and FMl outcomes. 
Very Early AR ( $\leq 43$ months)

O Early AR (by 61 months)

- Later AR (> 61 months)

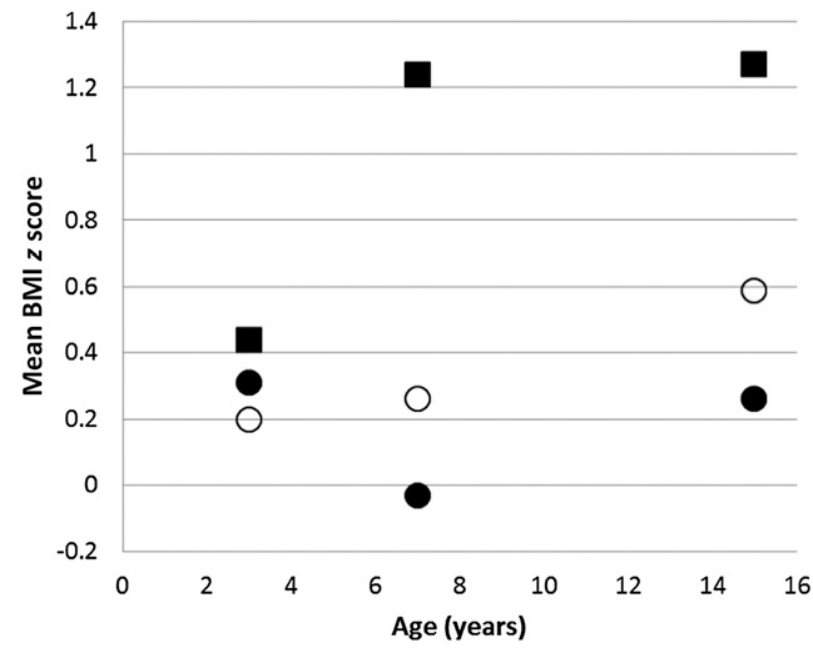

FIGURE 1

Mean BMI $z$ score by timing of AR across childhood and adolescence. BMI $z$ scores were calculated by using the UK 1990 population reference data. ${ }^{12}$

We observed large differences in adiposity outcomes at 15 years across AR categories, particularly between the very early group and the later AR group. $\mathrm{BMI}$ and $\mathrm{FMl}$ at 15 years were two-thirds of a SD higher for children with very early AR (by 3.5 years of age) compared with those with later AR ( $>5$ years of age). Table 2 shows that mean BMI $z$ score (externally derived) at 15 years was 1.27 (SD: 1.04) in the very early AR group (a BMI $z$ score $\geq 1.33$ defines clinical overweight in the United Kingdom) compared with 0.26 (SD: $1.07)$ in the later AR group. Fat mass and percentage of body fat were substantially higher (by $>7 \mathrm{~kg}$ and $10 \%$, respectively) among children with very early AR compared with those with later AR. The prevalence of overweight and obesity in adolescence was $58 \%$ in the very early AR group and $21 \%$ in the later AR group.

An interesting finding was the higher prevalence of parental obesity in the very early AR group (28\%) compared with the early (19\%) and later (14\%) AR groups, suggesting that young children of obese parents are at greater risk of earlier AR and therefore could be targets for preventive interventions. A detailed discussion of the early-life environmental factors associated with timing of AR is beyond the scope of the current study but has been discussed elsewhere. 2,5,24,25

A number of generally smaller and/or older studies have suggested that earlier AR increases obesity risk, as reviewed by Taylor et al. ${ }^{2} \mathrm{~A}$ recent study by Koyama et al ${ }^{6}$ found that an earlier AR $(<4$ years of age) was associated with a higher BMl and poorer cardiometabolic health at 12 years; however, the sample size was smaller than in the current study; BMI was measured at 12 years, whereas outcomes measured later in adolescence (as in the current study) are more likely to predict outcomes in adult life 26 ; and the influence of early AR on directly measured

TABLE 2 Comparison of Adiposity Measures at the 15-Year Research Clinic Across AR Categories

\begin{tabular}{|c|c|c|c|c|c|c|c|}
\hline & \multicolumn{2}{|c|}{$\begin{array}{l}\text { Very Early } A R(\leq 43 \text { Months) } \\
\qquad(n=63)\end{array}$} & \multicolumn{2}{|c|}{$\begin{array}{l}\text { Early AR (by } 61 \text { Months) } \\
\qquad(n=184)\end{array}$} & \multicolumn{2}{|c|}{$\begin{array}{l}\text { Later } \mathrm{AR}(>61 \text { Months }) \\
\qquad(n=660)\end{array}$} & \multirow[t]{2}{*}{ Difference $(P)$} \\
\hline & $n$ & Value & $n$ & Value & $n$ & Value & \\
\hline Age, mean $\pm S D$, mo & 39 & $184.5 \pm 2.3$ & 118 & $184.4 \pm 2.0$ & 399 & $184.2 \pm 2.1$ & .71 \\
\hline BMI $z$ score, ${ }^{\text {a }}$ mean \pm SD & 38 & $1.27 \pm 1.04$ & 116 & $0.59 \pm 1.21$ & 392 & $0.26 \pm 1.07$ & $<.001$ \\
\hline Fat mass, ${ }^{\mathrm{b}} \mathrm{kg}$ & 38 & $21.02(16.73,28.60)$ & 108 & $16.12(9.75,23.36)$ & 375 & $12.80(7.14,18.75)$ & $<.001$ \\
\hline $\mathrm{FMl}^{\mathrm{b}, \mathrm{c}} \mathrm{kg} / \mathrm{m}^{2}$ & 38 & $7.4(5.7,10.9)$ & 108 & $5.9(3.4,8.3)$ & 374 & $4.4(2.4,6.9)$ & $<.001$ \\
\hline Body fat, ${ }^{d}$ mean $\pm S D, \%$ & 38 & $32.3 \pm 11.3$ & 108 & $27.0 \pm 11.9$ & 374 & $22.3 \pm 10.8$ & $<.001$ \\
\hline Standardized residual of $\log B M{ }^{e},{ }^{e}$ mean $\pm S D$ & 38 & $0.88 \pm 1.15$ & 116 & $0.23 \pm 1.15$ & 392 & $-0.09 \pm 0.92$ & $<.001$ \\
\hline Standardized residual of $\log \mathrm{FMI}^{\mathrm{e}}$ mean $\pm \mathrm{SD}$ & 38 & $0.85 \pm 0.99$ & 108 & $0.23 \pm 1.14$ & 374 & $-0.12 \pm 1.01$ & $<.001$ \\
\hline Weight status, $n(\%)$ & 38 & & 116 & & 392 & & $<.001$ \\
\hline Healthy weight & & $16(42.1)$ & & $75(64.7)$ & & $310(79.1)$ & \\
\hline Overweight ${ }^{f}$ & & $7(18.4)$ & & $20(17.2)$ & & $45(11.5)$ & \\
\hline Obese $^{f}$ & & $15(39.5)$ & & $21(18.1)$ & & $37(9.4)$ & \\
\hline
\end{tabular}

a BMI $z$ scores calculated by using the UK 1990 population reference data. ${ }^{12}$

b Medians and IQRs are displayed for skewed variables.

c FMl calculated as fat mass in $\mathrm{kg} /$ height in $\mathrm{m}^{2}$.

d Percentage body fat calculated as fat mass in $\mathrm{kg} /$ measured weight in $\mathrm{kg}$.

e The outcome measures on which the associations between timing of AR and outcomes were conducted

${ }^{f}$ Overweight defined as BMl $z$ score $\geq 1.04$ and $<1.64$, equivalent to 85 th-94th percentiles; obese defined as BMl $z$ score $\geq 1.64$, equivalent to $\geq 95$ th percentile 
TABLE 3 Associations Between Timing of AR and Adiposity Outcomes at 15 Years

\begin{tabular}{|c|c|c|c|c|c|c|}
\hline & \multicolumn{3}{|c|}{ Very Early AR ( $\leq 43$ Months) ${ }^{\mathrm{a}}$} & \multicolumn{3}{|c|}{ Early AR (by 61 Months) ${ }^{a}$} \\
\hline & $\beta$ & $(95 \% \mathrm{Cl})$ & $P$ & $\beta$ & $(95 \% \mathrm{Cl})$ & $P$ \\
\hline \multicolumn{7}{|l|}{ BMI } \\
\hline Model $1(n=546)$ & 0.97 & $(0.64-1.30)$ & $<.001$ & 0.32 & $(0.12-0.53)$ & .002 \\
\hline Model $2(n=406)$ & 0.70 & $(0.35-1.05)$ & $<.001$ & 0.28 & $(0.05-0.50)$ & .02 \\
\hline Model $3(n=300)$ & 0.70 & $(0.33-1.07)$ & $<.001$ & 0.34 & $(0.08-0.59)$ & .009 \\
\hline \multicolumn{7}{|l|}{ FMI } \\
\hline Model $1(n=520)$ & 0.95 & $(0.60-1.30)$ & $<.001$ & 0.35 & $(0.13-0.57)$ & .002 \\
\hline Model $2(n=391)$ & 0.72 & $(0.36-1.09)$ & $<.001$ & 0.28 & $(0.04-0.53)$ & .02 \\
\hline Model $3(n=295)$ & 0.74 & $(0.34-1.15)$ & $<.001$ & 0.35 & $(0.07-0.63)$ & .02 \\
\hline
\end{tabular}

Model 1 (minimally adjusted $)=$ adjusted for age at the 15 -year research clinic and gender. Model 2 (partially adjusted $)=$ adjusted for model 1 plus parity, maternal education, household social class, at least 1 obese parent, any smoking in pregnancy, gestational age, and birth weight. Model 3 (fully adjusted) $=$ adjusted for model 3 plus pubertal status at the 15-year research clinic. Cl, confidence interval.

a Later AR group ( $>61$ months) is the reference category.

fat mass was not explored. Only 1 study ${ }^{10}$ to date has explored the association between timing of AR and direct assessment of adiposity in adulthood and reported results consistent with our own. This study ${ }^{10}$ by Ohlsson et al found that age at AR was a strong predictor of young adult men BMI, fat mass, and percentage body fat, and the associations were maintained after adjustment for BMI at AR. Subjects with early age at $\operatorname{AR}(<5.4$ years of age) had higher young adult BMI $(+8 \%)$ and fat mass $(+34 \%)$ compared with those with later age at AR. However, this study had several limitations, as discussed previously. Thus, the current study was the first to our knowledge to test for associations between timing of $A R$ and 2 measures of adiposity in adolescence including direct assessment of fat mass, adjusting for a wide range of potential confounders and using a relatively large contemporary sample in whom timing of AR had been established with the use of prospective childhood growth measures made in a research clinic and visual inspection of BMl-for-age plots, the "gold standard" for defining timing of $A R .1,15,16$

Early AR reflects excessive positive energy balance in early life $2,5,24,25$; therefore, influencing health behaviors (eg, toddlers' lifestyles) before the AR has occurred may reduce the risk of early AR and its sequelae. Our findings, together with evidence indicating that the AR occurs earlier now than in the past, $2,5,25,27,28$ provide a justification to policy makers and clinical practitioners to consider (1) more populationwide public health interventions in early childhood to delay timing of $A R$, (2) increased growth monitoring in early childhood to identify children at risk of early AR (eg, those with obese parents) or those who experienced early $A R$ and are therefore in greatest need of preventive efforts, and (3) more clinical interventions directed at these "high risk" children and their families.

Studies 29,30 have criticized the AR on the grounds that an early AR predicts later high fatness because it identifies children with a high BMI-for-age, and therefore BMI at or before the AR may be better predictors of later outcomes. However, these studies ${ }^{29,30}$ examined the association between age at AR and the BMI pattern of centile curves constructed cross-sectionally, which led to high BMls at all ages on the high centiles, whereas studies,10,24 using individual longitudinal assessment have shown that many children who rebound early have a normal or low BMl at or before the rebound followed by an increased BMI after the rebound. These findings are supported by our data (see Table 1 and Fig 1), which show that mean BMI $z$ scores were within the healthy range and similar across $A R$ categories at 37 months (ie, before the rebound had occurred) but were significantly higher in the very early and early AR categories after the rebound had occurred at 61 months and 7 years, respectively, in these children. Thus, this evidence highlights the importance of BMl trajectories in early childhood rather than focusing on a single measure of BMI at or before the AR. Concerns have also been raised whether an early AR reflects increased fat or lean mass and whether the increase in BMl observed in adolescents and adults who have experienced early rebound is due to an increase in body fat. ${ }^{26}$ Evidence ${ }^{1,5,8,24,31-34}$ indicates that early AR is attributable to an increase in body fatness (rather than alterations in lean mass) arising from "obesogenic" lifestyles in early life, and our results confirm that the high $\mathrm{BMI}$ observed in later life is due to increased fat mass.

The current study had some weaknesses. Loss to follow-up is inevitable in all cohort studies. Of the 907 children in whom AR was derived, $60.2 \%$ had BMl outcome data at age 15 and $57.3 \%$ had outcome data for FMI. Although slight differences in some maternal and social characteristics were observed between participants who provided BMI data at the 15-year research clinic and those who did not (see Supplemental Information), BMI $z$ scores in childhood and pubertal status at the 15-year follow-up were similar between groups and so it seems likely that loss to follow-up at 15 years did not have a marked impact on study findings. In addition, restricting the minimally adjusted analyses to those with complete data on all confounders produced similar regression coefficients (see Supplemental 
Information), again suggesting that missing data did not bias results. In the current study, follow-up was undertaken at age 15 rather than in adult life, but adiposity outcomes at age 15 would be strongly predictive of outcomes in adult life. ${ }^{26}$ Furthermore, most participants were in pubertal stages 4 and 5 by the time of the 15year research clinic and pubertal status was similar across the AR categories and did not alter associations between timing of AR and outcomes. Although the association between timing of $A R$ and outcomes was only slighted attenuated after adjustment for a number of potential confounding factors, other potential confounders

\section{REFERENCES}

1. Rolland-Cachera MF, Deheeger M, Bellisle F, Sempé M, Guilloud-Bataille M, Patois $E$. Adiposity rebound in children: a simple indicator for predicting obesity. Am J Clin Nutr. 1984;39(1):129-135

2. Taylor RW, Grant AM, Goulding A, Williams S. Early adiposity rebound: a review of papers linking this to subsequent obesity in children and adults. Curr Op Clin Nutr Metab Care. 2005;8(6):607-611

3. Reilly JJ, Armstrong J, Dorosty AR, et al; Avon Longitudinal Study of Parents and Children Study Team. Early life risk factors for obesity in childhood: cohort study. BMJ. 2005;330(7504):1357-1362

4. Whitaker RC, Pepe MS, Wright JA, Seidel KD, Dietz WH. Early adiposity rebound and the risk of adult obesity. Pediatrics. 1998;101 (3). Available at: www.pediatrics.org/cgi/ content/full/101/3/E5

5. Rolland-Cachera MF, Deheeger M, Maillot M, Bellisle F. Early adiposity rebound: causes and consequences for obesity in children and adults. Int $J$ Obes (Lond). 2006;30 (suppl 4):S11-S17

6. Koyama S, Ichikawa G, Kojima M, Shimura $\mathrm{N}$, Sairenchi T, Arisaka 0. Adiposity rebound and the development of metabolic syndrome. Pediatrics. 2014;133(1). Available at: www.pediatrics.org/cgi/content/full/133/1/ e114 may have been missed (eg, gestational diabetes and more recent measures of socioeconomic position). Finally, generalizability of the current study findings to other ethnic groups and populations from different settings should also be considered with caution because the influence of timing of $A R$ on later obesity might be different.

\section{CONCLUSIONS}

The current study suggests that early $A R$ is strongly associated with increased $\mathrm{BMI}$ and fatness in adolescence. If modifiable, the timing of $A R$ may be a novel target for future population-based preventive interventions by targeting modifiable factors in early life to delay timing of AR. Furthermore, routine identification of the timing of AR could identify young children at increased risk of obesity in later life and who are therefore in greatest need of preventive interventions.

\section{ACKNOWLEDGMENTS}

We thank all the families who took part in this study, the midwives for their help in recruiting them, and the whole ALSPAC team, which includes interviewers, computer and laboratory technicians, clerical workers, research scientists, volunteers, managers, receptionists, and nurses.
7. Freedman DS, Kettel Khan L, Serdula MK, Srinivasan SR, Berenson GS. BMI rebound, childhood height and obesity among adults: the Bogalusa Heart Study. Int J Obes Relat Metab Disord. 2001;25(4):543-549

8. Williams SM. Weight and height growth rate and the timing of adiposity rebound. Obes Res. 2005;13(6):1123-1130

9. Rolland-Cachera MF, Deheeger M, Avons P, Guilloud-Bataille M, Patois E, Sempé M. Tracking the development of adiposity from one month of age to adulthood. Ann Hum Biol. 1987;14(3):219-229

10. Ohlsson C, Lorentzon M, Norjavaara E, Kindblom JM. Age at adiposity rebound is associated with fat mass in young adult males-the GOOD study. PLOS ONE. 2012;7 (11):e49404

11. Boyd A, Golding J, Macleod J, et al. Cohort profile: the 'children of the 90s'-the index offspring of the Avon Longitudinal Study of Parents and Children. Int J Epidemiol. 2013; 42(1):111-127

12. Cole TJ, Freeman JV, Preece MA. Body mass index reference curves for the UK, 1990. Arch Dis Child. 1995;73(1):25-29

13. Reilly JJ, Dorosty AR, Emmett PM; Avon Longitudinal Study of Pregnancy and Childhood Study Team. Identification of the obese child: adequacy of the body mass index for clinical practice and epidemiol- ogy. Int J Obes Relat Metab Disord. 2000;24 (12):1623-1627

14. Reilly JJ, Dorosty AR, Ghomizadeh NM, Sherriff A, Wells JC, Ness AR. Comparison of waist circumference percentiles versus body mass index percentiles for diagnosis of obesity in a large cohort of children. Int $J$ Pediatr Obes. 2010;5(2):151-156

15. Kroke A, Hahn S, Buyken AE, Liese AD. A comparative evaluation of two different approaches to estimating age at adiposity rebound. Int J Obes (Lond). 2006;30(2):261266

16. Dorosty AR, Emmett PM, Cowin S, Reilly JJ; ALSPAC Study Team. Factors associated with early adiposity rebound. Pediatrics. 2000;105(5):1115-1118

17. Basterfield L, Pearce MS, Adamson AJ, Parkinson KN, Reilly JJ; Gateshead Millennium Study Core Team. Effect of choice of outcome measure on studies of the etiology of obesity in children. Ann Epidemiol. 2012;22(12):888-891

18. Ness AR, Leary SD, Mattocks C, et al. Objectively measured physical activity and fat mass in a large cohort of children. PLoS Med. 2007;4(3):e97-e105

19. Office of Population Census and Surveys. Standard Occupational Classification. London, United Kingdom: Her Majesty's Stationary Office; 1991 
20. Lawlor DA, Benfield L, Logue J, et al. Association between general and central adiposity in childhood, and change in these, with cardiovascular risk factors in adolescence: prospective cohort study. BMJ. 2010;341:c6224-c6235

21. Riddoch CJ, Leary SD, Ness AR, et al. Prospective associations between objective measures of physical activity and fat mass in 12-14 year old children: the Avon Longitudinal Study of Parents and Children (ALSPAC). BMJ. 2009;339:b4544-b4553

22. Hughes AR, Sherriff A, Lawlor DA, Ness AR, Reilly JJ. Timing of excess weight gain in the Avon Longitudinal Study of Parents and Children (ALSPAC). Pediatrics. 2011;127(3). Available at: www.pediatrics.org/cgi/content/full/127/3/e730

23. Hughes AR, Sherriff A, Lawlor DA, Ness AR, Reilly JJ. Incidence of obesity during childhood and adolescence in a large contemporary cohort. Prev Med. 2011;52 (5):300-304
24. Rolland-Cachera MF, Péneau S. Growth trajectories associated with adult obesity. World Rev Nutr Diet. 2013;106:127-134

25. Reilly JJ. Physical activity, sedentary behaviour and energy balance in the preschool child: opportunities for early obesity prevention. Proc Nutr Soc. 2008;67(3):317325

26. Reilly JJ, Methven E, McDowell ZC, et al. Health consequences of obesity. Arch Dis Child. 2003;88(9):748-752

27. Kowal M, Kryst $€$, Woronkowicz A, Sobiecki J, Brudecki J, Żarów R. Long-term changes in BMI and adiposity rebound among girls from Kraków (Poland) over the last 30 years (from 1983 to 2010). Am J Hum Biol. 2013;25(3):300-306

28. Johnson W, Soloway LE, Erickson D, et al. A changing pattern of childhood BMI growth during the 20th century: $70 \mathrm{y}$ of data from the Fels Longitudinal Study. Am J Clin Nutr. 2012;95(5):1136-1143
29. Dietz WH. "Adiposity rebound": reality or epiphenomenon? Lancet. 2000;356(9247): 2027-2028

30. Cole TJ. Children grow and horses race: is the adiposity rebound a critical period for later obesity? BMC Pediatr. 2004;4:6-9

31. Taylor RW, Goulding A, Lewis-Barned NJ, Williams SM. Rate of fat gain is faster in girls undergoing early adiposity rebound. Obes Res. 2004;12(8):1228-1230

32. Williams SM, Goulding A. Patterns of growth associated with the timing of adiposity rebound. Obesity (Silver Spring). 2009;17(2): 335-341

33. Campbell MW, Williams J, Carlin JB, Wake $M$. Is the adiposity rebound a rebound in adiposity? Int J Pediatr Obes. 2011;6(2-2) e207-e215

34. Taylor RW, Williams SM, Carter PJ, Goulding A, Gerrard DF, Taylor BJ. Changes in fat mass and fat-free mass during the adiposity rebound: FLAME study. Int $J$ Pediatr Obes. 2011;6(2-2):e243-e251 
Timing of Adiposity Rebound and Adiposity in Adolescence

Adrienne R. Hughes, Andrea Sherriff, Andrew R. Ness and John J. Reilly Pediatrics 2014;134;e1354; originally published online October 13, 2014; DOI: $10.1542 /$ peds. $2014-1908$

\section{Updated Information \& Services}

Supplementary Material

\section{References}

Subspecialty Collections

Permissions \& Licensing

Reprints including high resolution figures, can be found at: /content/134/5/e1354.full.html

Supplementary material can be found at: /content/suppl/2014/10/08/peds.2014-1908.DCSupplemental. html

This article cites 32 articles, 12 of which can be accessed free at:

/content/134/5/e1354.full.html\#ref-list-1

This article, along with others on similar topics, appears in the following collection(s):

Obesity

/cgi/collection/obesity_new_sub

Public Health

/cgi/collection/public_health_sub

Information about reproducing this article in parts (figures, tables) or in its entirety can be found online at:

/site/misc/Permissions.xhtml

Information about ordering reprints can be found online: /site/misc/reprints.xhtml

PEDIATRICS is the official journal of the American Academy of Pediatrics. A monthly publication, it has been published continuously since 1948. PEDIATRICS is owned, published, and trademarked by the American Academy of Pediatrics, 141 Northwest Point Boulevard, Elk Grove Village, Illinois, 60007. Copyright @ 2014 by the American Academy of Pediatrics. All rights reserved. Print ISSN: 0031-4005. Online ISSN: 1098-4275. 


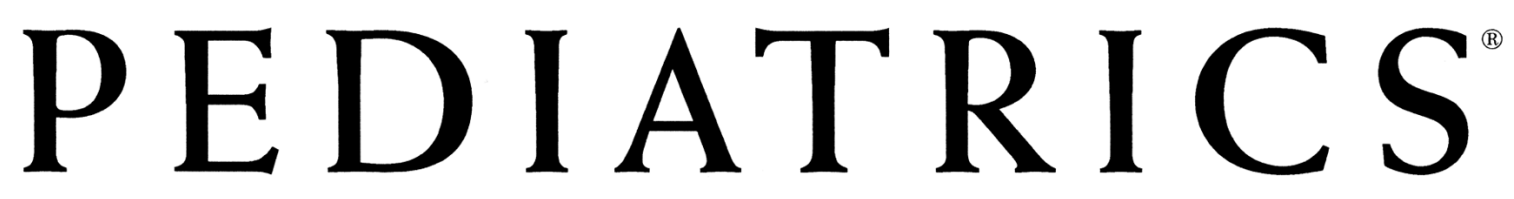

OFFICIAL JOURNAL OF THE AMERICAN ACADEMY OF PEDIATRICS

Timing of Adiposity Rebound and Adiposity in Adolescence

Adrienne R. Hughes, Andrea Sherriff, Andrew R. Ness and John J. Reilly Pediatrics 2014;134; e1354; originally published online October 13, 2014;

DOI: $10.1542 /$ peds.2014-1908

The online version of this article, along with updated information and services, is located on the World Wide Web at:

/content/134/5/e1354.full.html

PEDIATRICS is the official journal of the American Academy of Pediatrics. A monthly publication, it has been published continuously since 1948. PEDIATRICS is owned, published, and trademarked by the American Academy of Pediatrics, 141 Northwest Point Boulevard, Elk Grove Village, Illinois, 60007. Copyright (@) 2014 by the American Academy of Pediatrics. All rights reserved. Print ISSN: 0031-4005. Online ISSN: 1098-4275.

\section{American Academy of Pediatrics}

DEDICATED TO THE HEALTH OF ALL CHILDREN ${ }^{m}$ 